\title{
Robust Current Control of Doubly Fed Wind Turbine Generator under Unbalanced Grid Voltage Conditions
}

\author{
Wang, Yun; Gong, Wenming; Wu, Qiuwei
}

Published in:

Proceedings of IEEE PES APPEEC 2013

Publication date:

2014

Link back to DTU Orbit

Citation (APA):

Wang, Y., Gong, W., \& Wu, Q. (2014). Robust Current Control of Doubly Fed Wind Turbine Generator under Unbalanced Grid Voltage Conditions. In Proceedings of IEEE PES APPEEC 2013 [0146] IEEE.

\section{General rights}

Copyright and moral rights for the publications made accessible in the public portal are retained by the authors and/or other copyright owners and it is a condition of accessing publications that users recognise and abide by the legal requirements associated with these rights.

- Users may download and print one copy of any publication from the public portal for the purpose of private study or research.

- You may not further distribute the material or use it for any profit-making activity or commercial gain

- You may freely distribute the URL identifying the publication in the public portal

If you believe that this document breaches copyright please contact us providing details, and we will remove access to the work immediately and investigate your claim 


\section{Robust Current Control of Doubly Fed Wind Turbine Generator under Unbalanced Grid Voltage Conditions}

\author{
Yun Wang \\ College of Mechatronics and Control \\ Engineering, Shenzhen University \\ Shenzhen, P.R.China \\ wangyun@szu.edu.cn
}

\author{
Wenming Gong \\ University of Chinese Academy of \\ Sciences, Institute of Electrical \\ Engineering, Chinese Academy of \\ Sciences, Beijing, P.R.China
}

\author{
Qiuwei Wu \\ Centre for Electric Power and Energy \\ (CEE), Department of Electrical \\ Engineering, \\ Technical University of Denmark
}

\begin{abstract}
This paper presents the design of a $\mathbf{H} \infty$ current controller for doubly fed induction generators (DFIGs) in order to maintain stable operation under unbalanced voltage conditions. The $H \infty$ current controller has a multi-input and multi-output (MIMO) structure and is designed using the loop shaping method. Case studies have been carried out in order to verify the efficacy of the proposed $H \infty$ current controller for DFIGs. The case study results show that the proposed $\mathbf{H} \infty$ current controller can realize different control objectives, i.e. stable stator current, stable stator active power and stable stator reactive power. It is also shown that the $H \infty$ current controller is less sensitive to the parameter perturbation.
\end{abstract}

Index Terms-- DFIG, H $\infty$ current controller, MIMO, unbalanced voltage conditions

\section{INTRODUCTION}

Unbalanced voltage conditions in power systems are one of the frequent fault conditions during operations [1], [2]. Because the stator of doubly fed induction generators (DFIGs) is directly connected to the grid and the negative sequence impedance of DFIGs is usually small, the unbalanced voltage conditions will cause current unbalance, armature overheating, torque and power pulsation, etc. and will impact the secure and stable operation of DFIGs [2]-[4].

The control methods for DFIGs under unbalanced voltage conditions can be divided into two groups: (1) obtain the positive and negative sequence components of voltages and currents by positive and negative sequence separation, and implement closed loop current control using PI controllers in the positive and negative synchronous rotating frames [3]-[7]. Although the theory of such control methods is simple, the control system is complex and consists of a number of PI controllers. (2) replace PI controllers with more advanced controllers in order to realize better AC current pulsation following characteristics for rotor currents. Among the advanced controllers, the proportional resonant (PR) control or proportional integral resonant (PIR) controller is the most commonly used one [8], [9]. However, the performance of the PR controller depends on the resonant point parameters and the parameters should be adjusted according to the machine speed change, therefore, the applications of such methods are limited.

In practice, the operating conditions of wind turbine generators (WTGs) is very complex and the existing methods have not considered the impact of machine parameter change and disturbance uncertainties on the performance of the complex control system. Since the $\mathrm{H} \infty$ control has successful applications when there are uncertainties of model parameters and disturbances, the robust control method is used to develop a control scheme for DFIGs under unbalanced voltages in order to handle the AC pulsation disturbances. The proposed robust current controller for DFIGs is developed by using the loop shaping method to efficiently suppress the AC pulsation under unbalanced voltage condition. The case study results show that the proposed robust current controller has better robustness and reliability compared to the PIR controller.

\section{MATHEMATICAL MODEL OF DFIGS}

In the synchronous rotating reference frame, with the rotor side voltage and current converted to the stator side, the equivalent circuit of DFIGs is shown in Figure 1.

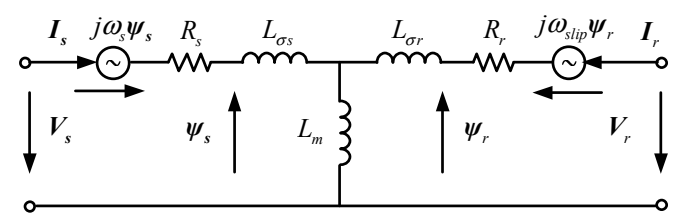

Figure 1 Equivalent circuit model of DFIG

The mathematical model of DFIGs is represented by (1) and (2). Since there is no neutral connection for the DFIG grid connection and hence no zero sequence loop, any vector of DFIGs can be decomposed into positive sequence and negative sequence components. 


$$
\begin{gathered}
\left\{\begin{array}{l}
\boldsymbol{\psi}_{s}=l_{s} \boldsymbol{I}_{s}+l_{m} \boldsymbol{I}_{r} \\
\boldsymbol{\psi}_{r}=l_{m} \boldsymbol{I}_{s}+l_{r} \boldsymbol{I}_{r}
\end{array}\right. \\
\left\{\begin{array}{c}
\boldsymbol{V}_{s}=r_{s} \boldsymbol{I}_{s}+\frac{1}{\omega_{B}} \frac{d \boldsymbol{\psi}_{s}}{d t}+j \omega_{s} \boldsymbol{\psi}_{s} \\
\boldsymbol{V}_{r}=r_{r} \boldsymbol{I}_{r}+\frac{1}{\omega_{B}} \frac{d \boldsymbol{\psi}_{r}}{d t}+j \omega_{s i l p} \boldsymbol{\psi}_{r}
\end{array}\right. \\
\omega_{s l i p}=\omega_{s}-\omega_{r}
\end{gathered}
$$

According to the symmetric component method, any vector can be decomposed into positive and negative components and projected to the positive and negative sequence synchronous rotating coordinate reference which is shown in Figure 2.

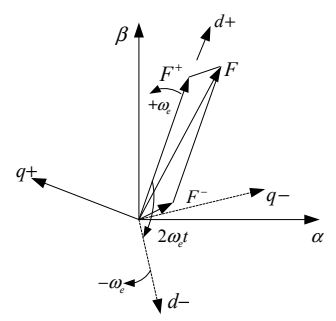

Figure 2 projections of vector $\mathrm{F}$ on positive and negative sequence synchronous rotating coordinate reference frames

Because the wind turbine generators (WTGs) and the grid connection circuits are usually three phase without neutral, there is no zero sequence loop. The DFIG model can be decomposed into positive and negative sequence components. In the decomposed model, the superscripts ' + ' and '-' denote the positive sequence and negative sequence rotating reference frame, and the subscripts ' + ' and '-' denotes the positive and negative sequence components. According to [13], the control commands of negative sequence current can be divided intro three categories:

1) To realize balanced rotor current in order to avoid unbalanced heating in the rotor windings.

$$
\left\{\begin{array}{l}
I_{\mathrm{rd}-}^{-*}=0 \\
I_{\mathrm{rq}-}^{-*}=0
\end{array}\right.
$$

2) To realize stable stator active power output in ordert o ensure stable active power outpout from wind power plants

$$
\left\{\begin{array}{l}
I_{\mathrm{rq}-}^{-*}=\frac{V_{\mathrm{sq}-}^{-}}{V_{\mathrm{sd}+}^{+}} I_{\mathrm{rd}+}^{+}-\frac{V_{\mathrm{sd}-}^{-}}{V_{\mathrm{sd}+}^{+}} I_{\mathrm{rq}+}^{+}-\frac{2 V_{\mathrm{sd}-}^{-}}{\omega_{\mathrm{s}} L_{\mathrm{m}}} \\
I_{\mathrm{rd}-}^{-*}=-\frac{2 V_{\mathrm{sq}-}^{-}}{\omega_{\mathrm{s}} L_{\mathrm{m}}}-\frac{V_{\mathrm{sd}-}^{-}}{V_{\mathrm{sd}+}^{+}} I_{\mathrm{rd}+}^{+}-\frac{V_{\mathrm{sq}-}^{-}}{V_{\mathrm{sd}+}^{+}} I_{\mathrm{rq}+}^{+}
\end{array}\right.
$$

3) To realize stable stator reactive power output

Shenzhen government Technology Project (JCYJ20120613170340342 and GJHZ20130408173747552)

$$
\left\{\begin{array}{l}
I_{\mathrm{rd}-}^{*}=\frac{V_{\mathrm{sd}-}^{-}}{V_{\mathrm{sd}+}^{+}} I_{\mathrm{rd}+}^{+}+\frac{V_{\mathrm{sq}-}^{-}}{V_{\mathrm{sd}+}^{+}} I_{\mathrm{rq}+}^{+} \\
I_{\mathrm{rq}-}^{-*}=\frac{V_{\mathrm{sq}-}^{-}}{V_{\mathrm{sd}+}^{+}} I_{\mathrm{rd}+}^{+}-\frac{V_{\mathrm{sd}-}^{-}}{V_{\mathrm{sd}+}^{+}} I_{\mathrm{rq}+}^{+}
\end{array}\right.
$$

\section{DESIGN OF Ho CURRENT CONTROLLER FOR DFIGs}

\section{A. Design of Ho Controller using the Loop Shaping Method}

The objective of the $\mathrm{H} \infty$ controller is to efficiently track the positive and negative sequence components of the machine rotor current and maintain the stability of the control system under certain types of disturbances.

According to the $\mathrm{H} \infty$ control formulation, (1) and (2) can be rewritten as (7) - (11).

$$
\begin{aligned}
& G:\left\{\begin{array}{c}
\dot{\boldsymbol{x}}=A \boldsymbol{x}+B_{1} \boldsymbol{d}+B_{2} \boldsymbol{u} \\
\boldsymbol{y}=C \boldsymbol{x}
\end{array}\right. \\
& \boldsymbol{x}=\left[\begin{array}{llll}
I_{s d} & I_{s q} & I_{r d} & I_{r q}
\end{array}\right]^{T} \\
& \boldsymbol{d}=\left[\begin{array}{ll}
V_{s d} & V_{s q}
\end{array}\right]^{T} \\
& \boldsymbol{u}=\left[\begin{array}{ll}
V_{r d} & V_{r q}
\end{array}\right]^{T} \\
& \boldsymbol{y}=\left[\begin{array}{ll}
I_{r d} & I_{r q}
\end{array}\right]^{T}
\end{aligned}
$$

where $\mathrm{x}$ is the state variable, $\mathrm{d}$ is the disturbance, $\mathrm{u}$ is the control variable, $y$ is the measured value of the feedback.

Based on the above DFIG mathematical model, a multiinput and multi-output (MIMO) $\mathrm{H} \infty$ current controller has been designed using the loop shaping method and the diagram of the controller is shown in Figure 3. In Figure 3, G is the linearized model of the DFIG, Wp and $\mathrm{Wu}$ are error and control weight functions. $\mathrm{P}$ is the generalized control object, $\mathbf{z}_{1}$ and $\mathbf{z}_{2}$ are generalized outputs, $\mathrm{K}$ is the controller to be solved. All the signals in the figure are vectors and the transfer functions are matrices.

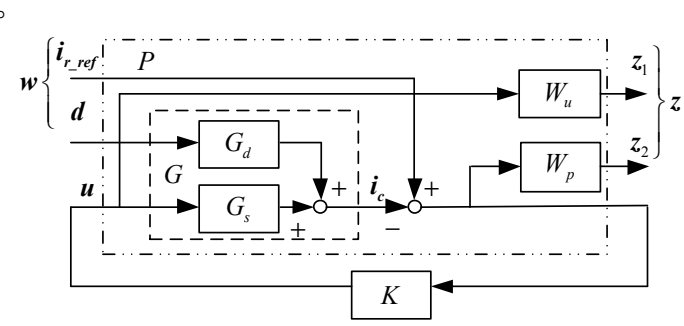

Figure 3. Diagram of DFIG Ho current controller

\section{B. Parameter designfor the $H \infty$ controller}

For the hybrid $\mathrm{H} \infty$ loop shaping issue, the design of the controller can be converted to find a stable controller $\mathrm{K}$ such that the closed loop transfer function of the generalized control object, $\mathrm{P}$, can meet the requirement that the $\mathrm{H} \infty$ norm is minimized, i.e. by defining a proper peak value margin $\gamma$ to ensure, 


$$
\left\|\begin{array}{ll}
W_{u} S_{i} K & -W_{u} S_{i} K G_{d} \\
W_{p} S_{o} & -W_{p} S_{o} G_{d}
\end{array}\right\|_{\infty}<\gamma
$$

where $\mathrm{S}_{\mathrm{i}}=\left(\mathrm{I}+\mathrm{KG}_{\mathrm{s}}\right)^{-1}$ and $\mathrm{S}_{\mathrm{o}}=\left(\mathrm{I}+\mathrm{G}_{\mathrm{s}} \mathrm{K}\right)^{-1}$ are input and output sensitivity functions.

(12) shows that the performance of the system mainly depends on the shapge of $\left\|1 / \mathrm{W}_{\mathrm{p}}\right\|_{\infty}$ and $\left\|1 / \mathrm{W}_{\mathrm{u}}\right\|_{\infty}$. Because the order of the $\mathrm{H} \infty$ controller is the sum of the order of the control object and the weight function, in order to reduce the difficulty of using the $\mathrm{H} \infty$ controller, it is important to select a weight function which can meet the control requirements and is with a low order.

After the weight function is selected, the optimal or suboptimal solution of the controller can be obtained by solving the Algebraic Riccati equations (the iterative calculation is required to obtain the solution). Because the per unit model is used, $\mathrm{W}_{\mathrm{u}}$ is set to 1 . In order to realize the control objective, a complex function weight function is defined,

$$
W_{p}=\frac{s / M+\omega_{1}}{s+\omega_{1} A}+\frac{k \omega_{n}^{2}}{s^{2}+2 \xi \omega_{n} s+\omega_{n}^{2}}
$$

Where the first part is for the basic control performance, the second part is to determine the control performance at the specified resonant frequency. $\omega_{1}(100 \mathrm{~Hz})$ is the low crossover frequency, due to the second part of the weight function, the bandwidth of the controller is larger than the cross-over frequency. It is good to constraint the rotor mode by increasing the bandwidth of the current controller, however, it will reduce the damping ratio of the stator mode. When the bandwidth of the current loop is approaching the resonance frequency, the system sensitivity will drastically increase at the stator mode frequency and the system capability against disturbances decrease. Therefore, it is better to set the current control bandwidth between the cross-over frequency and the resonance (synchronous??) frequency and limit the gain of T below $10 \mathrm{~dB}$. In this paper, $\omega_{n}=100 \mathrm{~Hz}, \quad \xi=0.02, \mathrm{k}=3$.

\section{Robust stability analysis}

When there are uncertainties of system parameters, the robust stability of a system can be quantified by calculating the structural singular value $\mu$,

$$
\mu=\frac{1}{\min \{\bar{\delta}(\Delta): \operatorname{det}(I-M \Delta)=0\}}
$$

When $\mu$ is less than 1 , the system is stable under all parameter perturbation. The smaller $\mu$ is, the better the system robustness is. According to the control bandwidth requirement explained in the previous section, a $\mathrm{H} \infty$ controller (K_Hinf) and a PIR controller have been designed and the singular value of the two controllers have been calculated which is shown in Figure. It is shown that the Ho controller is less sensitive to the parameter perturbation than the PIR controller.

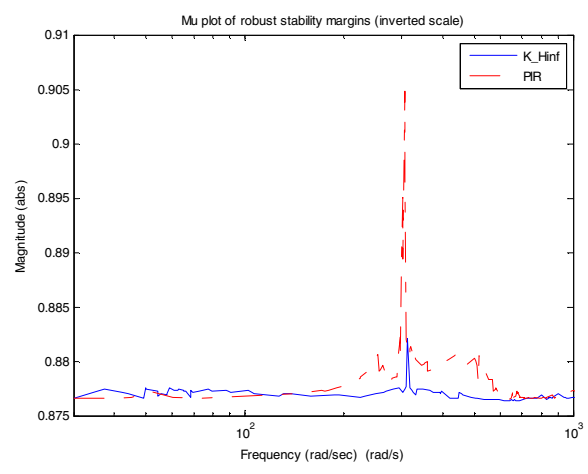

Figrue 4. Plot of structural (??) singular value $\mu$

\section{CASE StUdies}

In order to verify the efficacy of the proposed $\mathrm{H}_{\infty}$ controller, case studies have been carried out using MATLAB.

TABLE I. SIMULATION PROCESS DESCRIPTION

\begin{tabular}{|c|l|l|l|}
\hline $\mathrm{t}(\mathrm{s})$ & $5-5.2$ & $5.2-5.3$ & $5.3-5.4$ \\
\hline $\begin{array}{c}\text { Control } \\
\text { objectives }\end{array}$ & $\begin{array}{l}\text { Balanced } \\
\text { Rotor current }\end{array}$ & $\begin{array}{l}\text { Balanced Stator } \\
\text { active power }\end{array}$ & $\begin{array}{l}\text { Balanced Stator } \\
\text { reactive power }\end{array}$ \\
\hline
\end{tabular}

TABLE II. DFIG PARAMETERS

\begin{tabular}{|c|c|c|c|}
\hline $\begin{array}{c}\text { Stator } \\
\text { Resistance }\end{array}$ & $\begin{array}{c}0.00706 *(1 \pm 2 \%) \\
\mathrm{pu}\end{array}$ & $\begin{array}{c}\text { Rotor } \\
\text { Resistance }\end{array}$ & $\begin{array}{c}0.005^{*}(1 \pm 2 \%) \\
\mathrm{pu}\end{array}$ \\
\hline $\begin{array}{c}\text { Stator } \\
\text { Inductance }\end{array}$ & $\begin{array}{c}3.6710^{*}(1 \pm 2 \%) \\
\mathrm{pu}\end{array}$ & $\begin{array}{c}\text { Rotor } \\
\text { Inductance }\end{array}$ & $\begin{array}{c}3.656^{*}(1 \pm 2 \%) \\
\mathrm{pu}\end{array}$ \\
\hline $\begin{array}{c}\text { Mutual } \\
\text { inductance }\end{array}$ & $3.5 *(1 \pm 2 \%) \mathrm{pu}$ & $\begin{array}{c}\text { Rotor } \\
\text { speed }\end{array}$ & $1.2 \mathrm{pu}$ \\
\hline
\end{tabular}

The case study results are shon in Figure 5. The subpots are stator three phase voltage, stator dq axis currents, rotor dq axis currents, and stator active and reactive power from the top to the bottom. During the time period of $t=5 \sim 5.2 \mathrm{~s}$, the stator dq axis current waveforms do not have AC pulsation and are balanced, during the time period of $t=5.2 \sim 5.3 \mathrm{~s}$, by injecting certain stator negative current, the stator active power is stable, during the time period of $t=5.3 \sim 5.4 \mathrm{~s}$, the reactive power is stable. The case study results show that the $\mathrm{H} \infty$ controller can efficiently control the positive and negative components of the rotor current and realize the control objectives. 

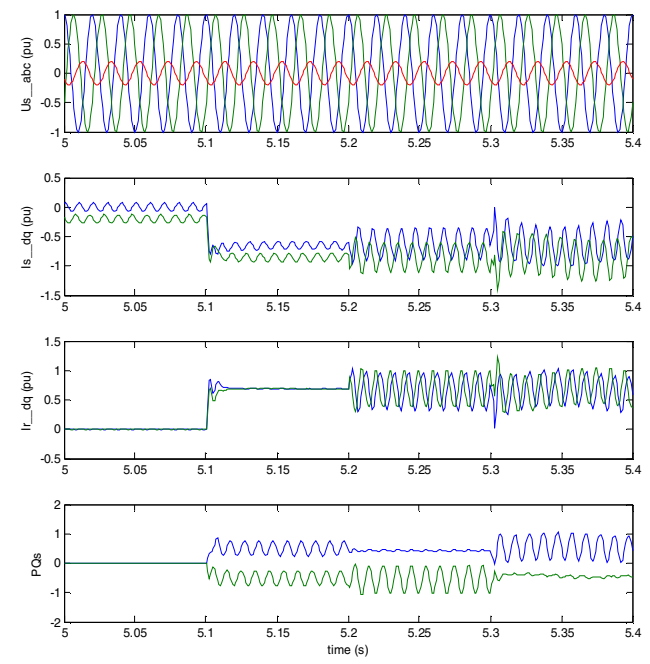

Figrue 5. Time domain simulation results

\section{CONCLUSION}

Under unbalanced voltage conditions, the rotor voltages and currents of DFIGs have negative sequence component. In order to keep stable operation of generators, it is essential to properly control the negative sequence component to realize different control objectives. An $\mathrm{H} \infty$ current controller for DFIGs is proposed in this paper and the efficacy of the proposed $\mathrm{H} \infty$ current controller has been verified by simulations.

The simulation results show that the proposed $\mathrm{H} \infty$ current controller has the following advantages.

1) The control system of DFIGs is simplified by replacing the conventional PI controller of the current control loop with the proposed $\mathrm{H} \infty$ current controller.

2) In the synchronous rotating frame, the proposed $\mathrm{H}_{\infty}$ current controller can realized multi-objective control and has better performance.

3) The comparison of the structure singular values shows that the proposed $\mathrm{H} \infty$ current controller has better robustness than the conventional PI controller and is less sensitive to the external disturbances or internal machine parameters.

\section{REFERENCES}

[1] Yikang He, Jiabing $\mathrm{Hu}$, "DFIG Wind Power Generation Systems During Unbalanced Network Fault: Analysis and Operation," in Proc. 2008 IEEE ICEMS Conf., pp. 2331-2336.

[2] Florin Iov, Anca Daniela Hansen, "Mappting of grid faults and grid codes," Riso National Laboratory Trchnical University of Denmark, 2007: 14-15.

[3] Lie Xu, Yi Wang, "Dynamic Modeling and Control of DFIG-Based Wind Turbines Under Unbalanced Network Conditions," IEEE Transactions on Power Systems, vol. 22, pp. 314-323, 2007.

[4] Yi Zhou, Bauer P, Ferreira JA, "Operation of Grid-Connected DFIG Under Unbalanced Grid Voltage Condition," IEEE Transactions on Energy Conversion, vol. 24, pp. 240-246, 2009.
[5] Pedro Rodriguez, Adrian V Timbus, " Flexible Active Power Control of Distributed Power Generation Systems During Grid Faults, " IEEE Transaction on Industrial Electronics, vol.54, pp. 2583-2591, 2009.

[6] Wang Y, Xu L, Williams B W, " Compensation of network voltage unbalance using doubly fed induction generator-based wind farms," IET on Renewable Power Generation, vol.3, pp. 12-22, 2009.

[7] Wang Yun, Cao Guangzhong, " Control of a DFIG-Based Wind Turbine under Unbalanced Grid Voltage Dips based on a New Method to Separate Positive and Negative Sequence Components,"Acta Energiae Solaris t., in press.

[8] Jiabing Hu, Yikang He, Lie Xu, Williams B W, " Improved Control of DFIG Systems During Network Unbalance Using PI-R Current Regulators," IEEE Transactions on Industrial Electronics, vol.56, pp. 439-451, 2009.

[9] Teodorescu R, Blaabjerg F, Liserre M, " Proportional-resonant Controllers and Filtersfor Grid-connected Voltage-source Converters, "IEEE Proceedings of Electric Power Applications, vol.153, pp. 750-762, 2006.

[10] Timbus AV, Ciobotaru M, Teodorescu R, " Adaptive Resonant Controller for Grid-Connected Converters in Distributed Power Generation Systems, " in Proc. 2006 IEEE Applied Power Electronics Conf., pp. 1601-1606.

[11] Willmann G, Coutinho D F, Pereira L F A, Libano F B, " MultipleLoop H-Infinity Control Design for Uninterruptible Power Supplies, " IEEE Transactions on Industrial Electronics, vol.54, pp. 1591-1602, 2007.

[12] Mei F, Pal B, " Modal Analysis of Grid-Connected Doubly Fed Induction Generators, "IEEE Transactions on Energy Conversion, vol.22, pp. 728-736, 2006. 